\title{
The Analysis of Drought Conditions in Tongchuan City, Shaanxi Province, China Based on the SPI Index
}

\author{
Lin Tao ${ }^{1}$, Du Jin-li ${ }^{2}$, Qian Hui ${ }^{1}$ \\ ${ }^{1}$ College of Environmental Science and Engineering, Chang'an University, Shaanxi, Xi'an, China \\ ${ }^{2}$ School of Economic Law, Northwest University of Politics and Law, Shaanxi, Xi'an, China \\ Emial address: \\ 870501641@qq.com (Lin Tao),764433080@qq.com (Du Jin-li), qianhui@chd.edu.cn (Qian Hui)
}

\section{To cite this article:}

Lin Tao, Du Jin-li, Qian Hui. The Analysis of Drought Conditions in Tongchuan City Based on the SPI Index. International Journal of Environmental Monitoring and Analysis. Vol. 3, No. 5, 2015, pp. 351-356. doi: 10.11648/j.ijema.20150305.27

\begin{abstract}
Based on the rainfall data of nearly 60 years in Tongchuan City, Shaanxi Province, China (the following abbreviated as tongchuan) the author makes a detailed study of the precipitation data in Tongchuan since the 21 st century by a detailed study. the author makes a detailed study of the precipitation data in Tongchuan since the 21 st century by a detailed study.In other words, the author researches standardized precipitation index in every year and reason in Tongchuan,in order to analyze standardized precipitation index and drought intensity in different years and season. The main conclusions were as follows:(1)in the past 60 years throughout a downward trend and change tendency rate was $-4.2831 \mathrm{~mm} / 10 \mathrm{a}$.(2)The drought conditions in the Tongchuan city has gradually increased since the 21 st century, especially in recent years, the intensity of drought in winter has been increase slowly.
\end{abstract}

Keywords: Tongchuan, Standardized Precipitation Index, the Intensity of the Drought, Precipitation

\section{基于SPI指数的中国陕西省铜川市干旱情况分析}

\author{
林涛 $^{1}$, 杜金丽 ${ }^{2}$, 钱会 ${ }^{1}$ \\ $1^{1}$ 环境科学与工程学院, 长安大学, 西安, 陕西, 中国 \\ 2经济法学院, 西北政法大学, 西安, 陕西, 中国
}

\section{邮箱}

870501641@qq.com（林涛）,764433080@qq.com（杜金丽）, qianhui@chd.edu.cn（钱会）

\begin{abstract}
摘要：基于中国陕西省铜川市（以下简称铜川市）近60年的降雨资料，采用标准化降雨指标数据统计方法，对铜川地 区研究序列内各年、季节标准化降水指数, 分析其在不同年、季节的标准化指数的变化及其干旱强度。结果表明: 1) 近60年来铜川市年降水量呈下降趋势, 变化倾向率为 $-4.2831 \mathrm{~mm} / 10 \mathrm{a} 。 2) 21$ 世纪以来铜川市的干旱情势逐渐严重, 特别 是近年来冬季干旱强度呈缓慢增加趋势的特点。
\end{abstract}

关键词: 铜川, 标准化降水指标, 干旱强度, 降水量

\section{1. 引言}

干早和洪水、台风、地震、火山爆发等一样, 都是对 人类威胁十分严重的自然灾害, 而干旱又有一个不同于其 它自然灾害的特点, 即其 “确定” 问题。洪水、台风、地
震和火山爆发等许多自然灾害的发生相对来讲是突然发 生的, 发展演变迅速, 一旦形成或发生就很容易观测到, 但 干旱的发生非常缓慢, 灾前无明显的征兆, 有时甚至直到 灾害已形成, 人们还未能意识到一次干旱已构成了危害 [1], 其开始和终止时间并不清楚, 只有灾后评估时才能明 确界定。这是干旱的特点, 也是干旱监测研究的难点。但 
由于干旱出现频率高、持续时间长、波及范围大, 对国民 经济特别是对农业生产有严重影响, 使人们对干旱指标的 研究更加重视和关注 [2-4]。其中一个地区干旱的发生它 包含着很多复杂的过程和致旱因子, 它不仅与降水的多少 和时空分配有关, 而且还与植物生长需水量、土壤含水量、 径流量等多种因子有关, 因此要研究一个地区的干旱情况, 必须的明确干旱因素跟干旱指标。干旱指标 [5]必须具有 足够的普遍适用性, 以便能在不同气候地区、不同时间尺 度下反映干旱的发生。干旱指标就其复杂程度而言, 是多
种多样的, 从简单的降水距平指标直到更为精确的作物水分参数模式, 该模式把同一个气候区的土壤温度和土地 使用管理结合起来加以考虑。但因为人、物、财的要求太 高, 所以对于大范围的干旱实时监测评价, 尤其是当考虑 许多气象站资料时, 运用考虑多因子的复杂指标是几乎不 可能的。基于降雨标准化指数能够较好的反映干旱强度以 及计算指数的资料容易获取的优点, 本文应用降雨标准化 指数法对 21 世纪以来铜川市的干旱问题进行研究。

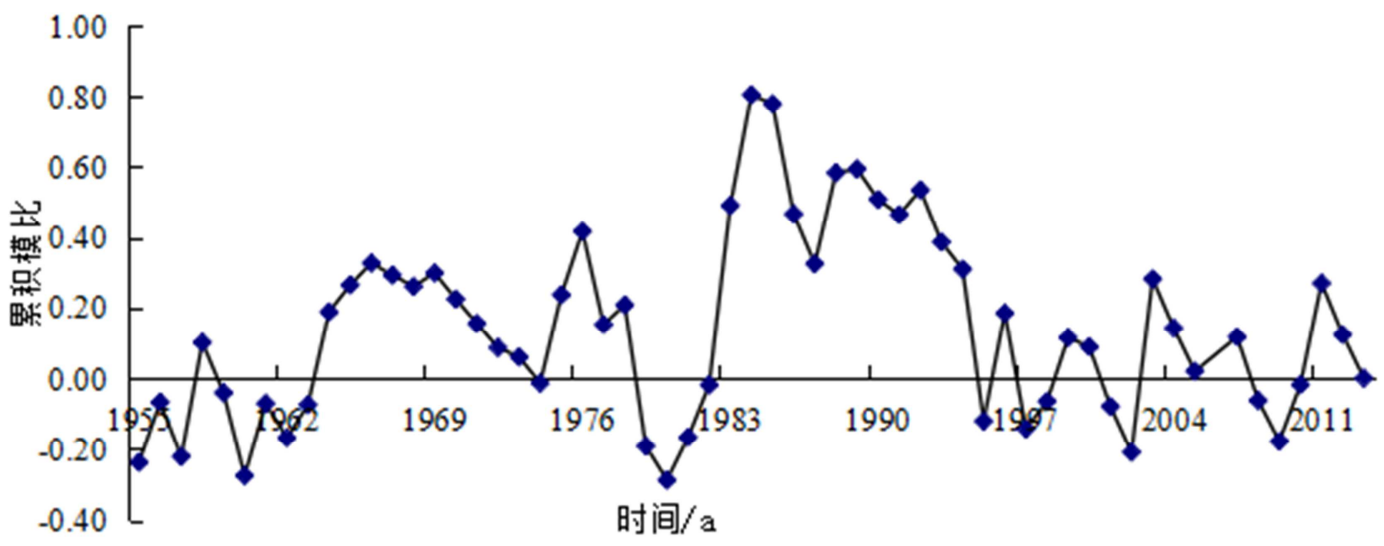

图1 1955一-2013年铜川市年降雨量模比系数差积曲线。

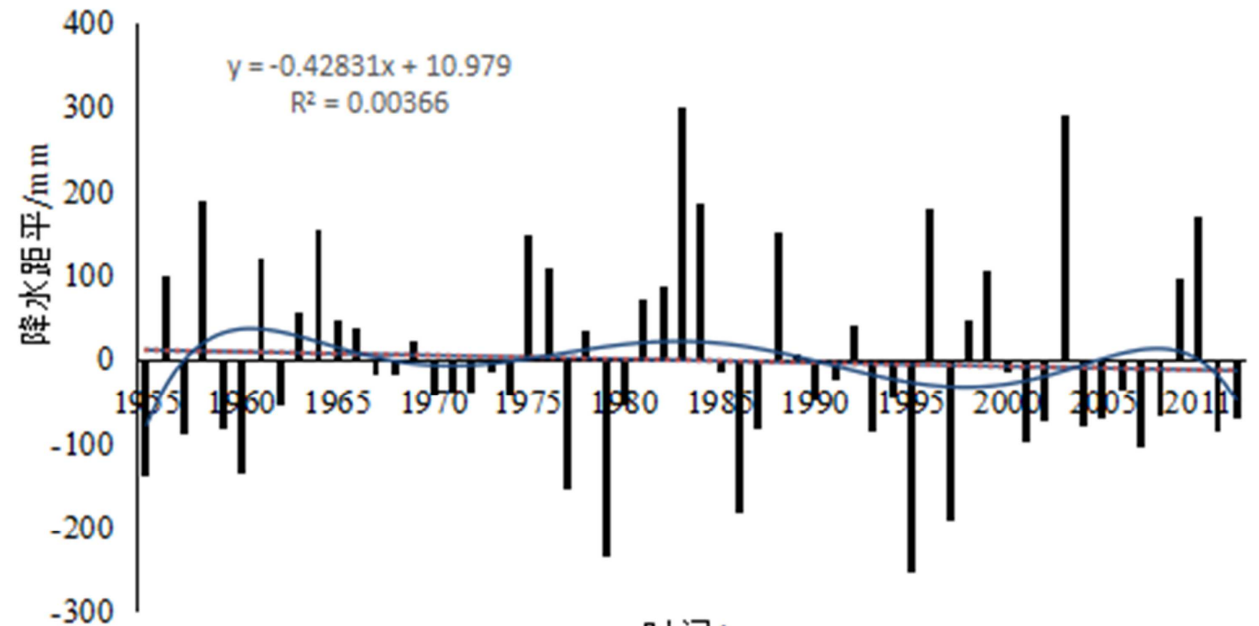

时间 $/ \mathrm{a}$

图2 1955-2013年铜川市降水距水平变化曲线。

\section{2. 资料分析}

\section{1. 研究区域概况}

铜川市位于陕西省中部, 地处渭北旱塬是关中盆地与 陕北黄土高原过渡带, 总土地面积为 $3882 \mathrm{~km}^{2}$, 地势呈西 北高、东南低走势, 海拔多在600-1700m之间。属暖温带半 干早半湿润大陆性季风气候, 四季分明, 冬长夏短, 雨量偏 少但集中, 夏、秋季易涝, 冬、春季易旱, 温度偏低, 地区 差异明显, 灾害比较频繁。全市年平均降雨量 550.8 - 709. 3mm, 水资源总量 $2.295 \times 10^{9} \mathrm{~m}^{3}$ ，地表径流量 $2.288 \times 10^{9} \mathrm{~m}^{3}$ ，地下水资源量 $0.929 \times 10^{9} \mathrm{~m}^{3}$ ，人均占有水
资源量相当于全国人均量的 $1 / 8$, 全省人均量的 $1 / 4$, 干 旱指数为 $1.71[6-7]$ 。各条河流流量悬殊较大， 50 \% $60 \%$ 以 上的水量集中在 $7 、 8 、 9$ 三个月, 形成洪水期, 而11月、 12月、1月和 2 月河水量仅占年径流量的 $10 \sim 18 \%$, 甚至出现 断流现象, 成为枯水期 [8]。社会经济的迅速发展使水资 源压力日趋严重, 旱灾对农业生产影响最大, 还影响工业 生产、群众生活和生态环境。干旱已成为制约铜川市发展 的因素之一。

\section{2. 降水年代特征}

本文利用铜川市 1955-2013年降水量测量资料, 选 21 世纪以来的降水量作为研究对象, 对比 21 世纪以来的 
降水量与近60年的降雨量变化情况图1。据统计, 铜川市 近60年来年平均降水为 $589 \mathrm{~mm}$, 降水的年际变化程度用 CV 值表示, 该地区近 60 年降水量的 CV 值为 0.198 , 反映了降 水的离散程度较小。由图1可以直观的看出近 60 年里铜川 市降水有丰枯交替变化的规律, 1980年出现最低点, 1984 年出现最高点。1976-1980、1986-1995、2011-2013 年差积曲线为下降段（枯水年），1963-1967、19801986、2002-2004、2009-2011年为上升段（丰水年）。 图 2 反映的是铜川市近 60 年来降水趋势, 从线性拟合直线 中看出, 从1955年来铜川市降水量总体呈减少趋势, 虽幅 度不大, 但降水的年际变化较大。利用6阶多项式拟合 [9] 的年平均降水曲线, 反映出 50 年代末 -60 年代末降水稍微 增加, 80 年代以来总体减少趋势。具体而言, 20 世纪 50 - 80 年代中期, 铜川市降水正、负距平相当, 说明这一时 期降水均匀。从 80 年代中期至今, 大部分年份为负距平, 特别是 1995 年降水距平为 $-253.37 \mathrm{~mm}$, 在所在研究年份里 达到最低, 说明该地区降水具有明显的减少趋势。从计算 结果看, 铜川市年降水变化的倾向率为 $-4.2831 \mathrm{~mm} / 10 \mathrm{a}$, 相关系数值为 0.061 。总之, 铜川市降水总体呈减少趋势, 与最近 50 年关中地区年平均降水量呈下降趋势相一致 [10]。

利用差计曲线和降水距平变化曲线对铜川地区年降 水量分析结果显示降水量呈下降趋势, 而降水量是对干旱 影响的重要因素之一, 为了对铜川市的干旱情况进一步研 究, 需要继续对铜川市降水资料进行分析。本文利用标准 化降雨指标法主要对铜川21世纪干旱情况进行研究。

\section{3. 研究方法}

\section{1. 标准降雨指数 (SPI)}

标准降水指数是表征某时段内降水量出现的概率多 少的指标之一，该指标是由McKee等[11]在评估美国科罗 拉多干旱状况时提出的。该指标适用于月以上尺度相对当 地气候状况的干旱监测与评估, 能较好的反映干旱强度和 持续时间, 而且有多时间尺度应用的特征, 因而得到广泛 应用。

SPI的原理基于降水量不是正态分布而是一种偏态分 布, 因此在进行降水量监测、评估中, 采用 $\Gamma$ 分布概率来 描述降水量的变化。SPI在对某时段内的降水量进行 $\Gamma$ 分布 概率计算后, 再进行正态标准化处理, 最终将偏态分布的 降水量标准化并用标准化后的降雨量累积频率分布来划 分干旱等级。

\subsection{1. 假设某一时段的降水量为 $x$, 则其 $\Gamma$ 分布概率密度 函数为式 (1) 所示}

$$
f(x)=\frac{1}{\beta^{\gamma} \Gamma(x)} x^{\gamma-1} e^{-x / \beta} \quad(x>0)
$$

式中, $\beta$ 为尺度参数; $\gamma$ 为形状参数; $x$ 为降水量; 可用极大拟然估计方法求得

$\beta$ 和 $\gamma$

$$
\begin{aligned}
& \hat{\gamma}=\frac{1+\sqrt{1+4 \mathrm{~A} / 3}}{4 \mathrm{~A}} \\
& \hat{\beta}=\frac{\bar{x}}{\hat{\gamma}}
\end{aligned}
$$

式(2)中的A为式 (4):

$$
A=\lg \bar{x}-\frac{1}{n} \sum_{i=1}^{n} \lg x_{i}
$$

式中: $x$ 为降水量平均值; $x_{i}$ 为降雨量资料样本。

确定概率密度函数中参数后, 对于某一年的降水量 $x_{0}$, 可求出随机变量 $x$ 小于 $x_{0}$ 事件的概率为式 (5)

$$
F\left(x<x_{0}\right)=\int_{0}^{x_{0}} f(x) d x
$$

将 (1) 式代入 (5) 式, 利用数值积分可以进行计算 事件概率的近似估计值。

\subsection{2. 降水量为零的事件概率由式 (6) 估计}

$$
F(x)=m / n
$$

式中: $m$ 为降雨量为 0 的样本数; $n$ 为总样本数。

3. 1.3. 对 $\Gamma$ 概率分布函数进行正态标准化处理, 即将(5) 与（6）式中求得的概率值代入标准正态分布函数 中

$$
F\left(x<x_{0}\right)=\frac{1}{\sqrt{2 \pi}} \int_{0}^{x_{0}} e^{z^{2} / 2} d x
$$

对式 (7) 进行变形近似求解可得到式 (8):

$$
Z=S\left[t-\frac{\left(c_{2} t+c_{1}\right)}{\left(\left(d_{3} t+d_{2}\right) t+d_{1}\right)+1.0}\right]
$$

其中: $t=\sqrt{\ln \left(1 / F^{2}\right)} F$ 为 (5) 式或 (6) 式求得的概 率; 当 $F>0.5$ 时, $F=1.0-F, S=1.0$; 当 $F<0.5$ 时, $S=-1.0, c_{0}=2.51557, c_{1}=0.802853, c_{2}=0.010328$, $d_{1}=1.432788, d_{2}=0.189269, d_{3}=0.001308$ 。

由 (8) 式求得的Z值就是标准化降雨指数SPI。

\section{2. 降水标准化指数的应用}

SPI是通过概率密度函数求解累积概率, 将累积概率 标准化, 计算过程中没有涉及与降水量的时空分布特性有 关的参数, 降低了指标计算的时空差异, 对不同时空的旱 涝状况都有良好的反映。相比较而言, SPI的计算更为稳 定。其优点是能使用任意时间尺度, 对于干旱的反映较灵 敏。目前国家气候中心运行以SPI和湿润度指数为基础, 
并考虑近期降水量的综合指数对全国范围的干旱实况进 行逐日滚动实时监测, 业务实践效果良好。

降水标准化指数的计算只需要对研究区连续多年降 雨量资料进行整理与计算, 其结果即可反映该研究区的 干旱状况。资料不仅获取容易, 也避免了数学模型繁杂 的计算和大量经验性的参数对计算结果的影响，同时又 抓住了反映干旱的主要因素一降水量。张强 [12]认为标 准化降水指数不仅考虑到降水服从偏态分布的实际, 而 且又进行了正态标准化处理, 从而使标准化降水指数适 合确定不同时间尺度的干旱检测、评价，具有相同干旱 等级划分标准, 能进行多时间尺度旱涝等级对比分析,
是一种较好的气候干旱指标, 其不足之处就是没有考虑 干旱发生的其他因子。

\section{4. 计算结果与评估情况}

选取铜川市1955-2013年降雨资料为基础, 逐个计算 2001-2013年铜川市各月以及各个季节的SPI值并确定各 月的以及各季节的干旱等级, 结果见表 1 和表 2 。图3 和图4 中纵坐标 1 表示无旱; 2 表示轻微干旱; 3 表示中等干旱; 4 表示严重干旱; 5表示特旱。

表1 2001-2013年铜川市各月降雨标准化指数统计表。

\begin{tabular}{lllllllllllll}
\hline 时间 & 1月 & 2月 & 3月 & 4月 & 5月 & 6月 & 7月 & 8月 & 9月 & 10月 & 11月 & 12月 \\
\hline 2001 & 1.38 & 0.67 & -1.83 & -0.52 & -1.5 & -0.08 & 0.21 & 1.04 & 0.97 & -0.3 & -0.96 & 0.73 \\
2002 & 0.53 & -0.3 & -0.48 & -0.84 & 1.11 & 0.52 & -0.9 & -0.08 & -0.21 & -1.04 & -0.47 & 1.39 \\
2003 & 1.28 & -0.17 & -0.48 & -0.04 & -0.04 & 0.38 & 0.17 & 1.38 & 1.28 & 1.65 & 0.97 & 0.3 \\
2004 & 0 & 1.83 & 0.13 & -1.38 & -1.04 & 0.13 & -0.25 & 0.21 & 0.34 & -0.21 & -0.62 & 1.65 \\
2005 & -1.19 & 0.17 & -1.19 & -0.43 & 0.21 & -0.04 & -1.19 & 0.3 & 0.62 & 0.34 & -0.73 & -0.12 \\
2006 & 1.19 & 0.97 & -1.50 & -1.11 & 0.57 & 1.38 & 0.48 & 0.84 & -0.17 & -0.13 & -0.29 & 0.48 \\
2007 & -0.90 & 1.11 & 1.28 & -2.13 & -0.78 & 0.13 & 1.11 & -0.17 & -0.38 & 0.43 & -1.03 & 0.91 \\
2008 & 2.13 & 0.48 & -0.17 & -0.17 & -1.83 & 1.50 & -0.62 & -0.73 & 0.00 & -0.17 & -0.38 & -1.27 \\
2009 & -1.10 & 1.19 & 0.48 & -0.38 & 1.19 & -1.04 & 0.25 & -0.43 & -0.34 & -0.90 & 1.11 & 0.43 \\
2010 & -1.72 & 0.78 & -0.34 & 0.38 & -0.30 & -0.25 & 1.38 & 1.04 & 0.21 & -0.57 & -1.28 & -0.20 \\
2011 & 0.09 & 1.04 & -0.84 & -0.30 & 0.43 & -1.11 & 0.13 & 0.52 & 2.13 & 0.97 & 1.83 & 0.26 \\
2012 & 0.21 & -0.90 & 0.30 & 0.04 & -0.17 & 0.78 & -0.84 & -0.34 & 0.78 & -2.13 & -0.78 & 0.34 \\
2013 & -0.12 & -0.67 & -1.64 & -0.25 & 0.84 & -0.34 & 1.50 & -1.65 & -0.08 & -0.84 & 0.04 & -1.27 \\
\hline
\end{tabular}

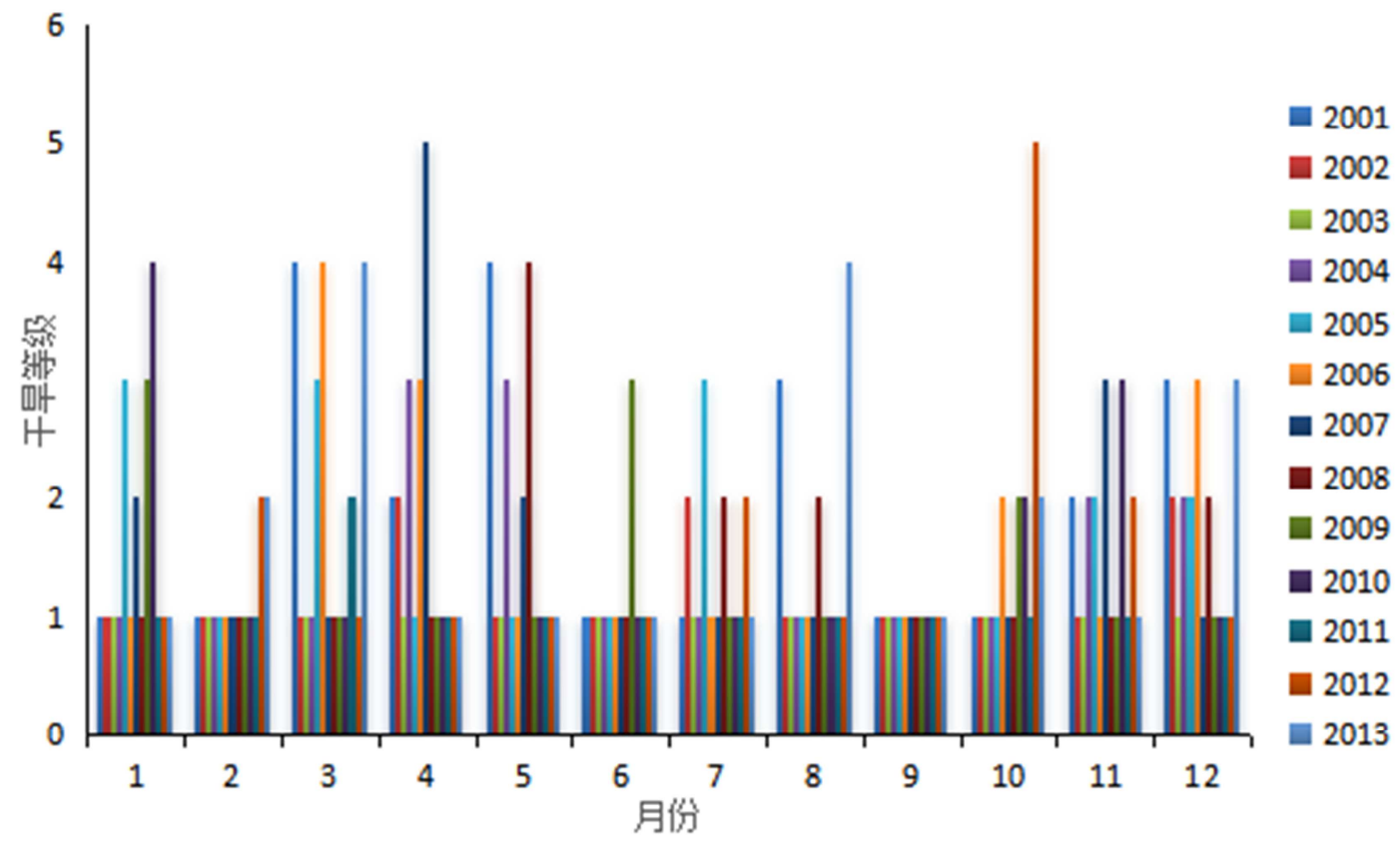

图3 2001-2013年铜川市各月干旱强度情况。

铜川市每年各个月份的干旱等级统计结果如下: 在研 究序列年中只有 9 月没有出现过干旱情况, 其他月份或轻 或重都有旱情出现。其中干旱情况较为严重的月份有 1 月、
3 月、4月、5月、10月、11月以及 12 月，铜川市发生不同 程度的干旱情况, 特别是 2007 年 4 月和 2012 年 10 月铜川市 发生了特旱。 
表2 2001-2013年铜川市各季节降雨标准化指数统计表。

\begin{tabular}{lllll}
\hline 时间 & 春季 & 夏季 & 秋季 & 冬季 \\
\hline 2001 & 严重干早 & 轻微干早 & 正常 & 严重湿润 \\
2002 & 正常 & 轻微干早 & 正常 & 轻微湿润 \\
2003 & 正常 & 中等湿润 & 严重湿润 & 正常 \\
2004 & 严重干早 & 正常 & 正常 & 严重湿润 \\
2005 & 轻微干旱 & 轻微干早 & 轻微湿润 & 轻微干早 \\
2006 & 正常 & 正常 & 正常 & 中等湿润 \\
2007 & 正常 & 中等湿润 & 正常 & 正常 \\
2008 & 正常 & 轻微湿润 & 轻微干早 & 轻微湿润 \\
2009 & 正常 & 严重湿润 & 中等干旱 & 正常 \\
2010 & 正常 & 轻微湿润 & 中等湿润 & 轻微干早 \\
2011 & 严重湿润 & 正常 & 正常 & 轻微湿润 \\
2012 & 正常 & 轻微湿润 & 正常 & 轻微干早 \\
2013 & 正常 & 正常 & 正常 & 中等干早 \\
\hline
\end{tabular}
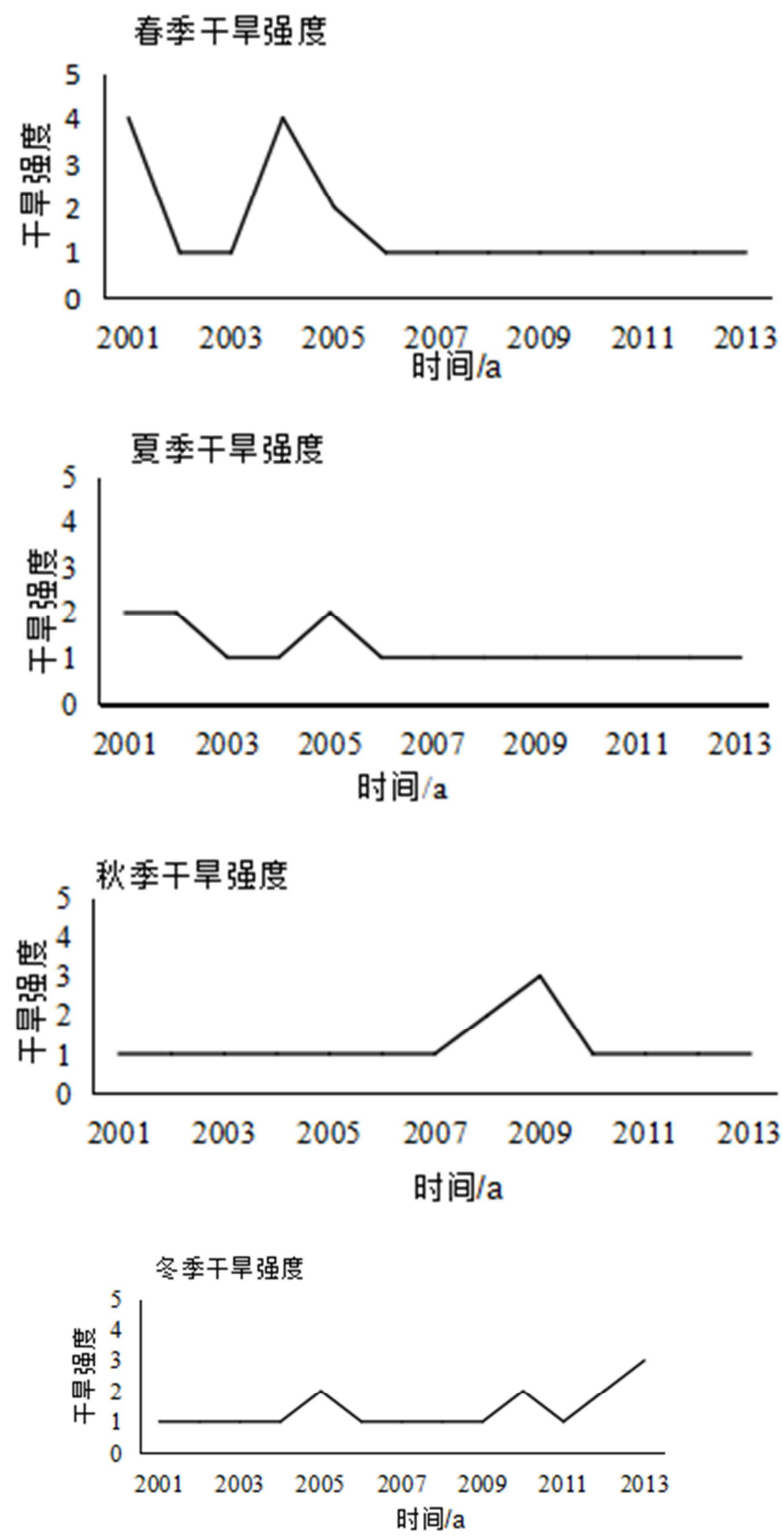

图4 2001-2013年铜川市各季节干旱强度情况。

铜川市2001年和2003-2006年春季出现微旱、中等干 旱、严重干旱不同等级的干旱情况, 夏季在 2001-2002
和2005年出现微旱情况, 在2005年发生春夏连旱。2007 - 2010年出现 21 世纪以来未曾发生过的秋旱, 并且其干旱 等级达到中等干旱。从2009年以来冬季出现间断性干旱并 呈现出持续干旱的旱情。

\section{5. 结论和讨论}

文中利用铜川市近60年降水资料的基础上, 分析了降 水变化的基本特征。采用标准降水指数法对该地区 21 世纪 以来的干旱情况进行分析。主要结论如下:

1) 自1955年以来铜川市的年降水量总体呈减少趋势, 利用一元线性拟合得出铜川市年际降水变化的递减率为 $-4.2831 \mathrm{~mm} / 10 \mathrm{a}$ 。总之, 铜川市降水总体呈减少趋势, 与最 近50年关中地区年平均降水量呈下降趋势相一致。

2) 进入 21 世纪初, 铜川市的年降水量较上世纪90年代 有上升趋势, 但降水量仍处于偏少的趋势, 因而干旱呈现 出逐渐严重现象。就各月的干旱情况而言, 铜川市全年干 旱情况严重的月份有1月、3月、4月、5月、10月、11月以 及 12 月, 且干旱强度呈上升趋势, 特别是 2012 年 10 月的干 旱强度达到 21 世纪以来最高, 月降水量仅占多年平均月降 水量的 $14.13 \%, \mathrm{SPI}$ 值达到 -2.13 。

3) 从铜川市各季节的干旱情况来看, 在 21 世纪初春、 夏季的干早情况严重, 特别是2001年和2004年春季达到严 重干旱程度。从2009年以来铜川市的冬季都处于微旱并逐 渐向中等干旱发展, 今后铜川市的干旱情势将有持续严重 的趋势。4)通过对干旱情况的分析可以为铜川市的干旱监 测和预防工作提供参考意见。

\section{致谢}

基金项目: 渭河中下段干旱预警与应急水源配置 (201301084)

\section{参考文献}

[1] Wilhite DA. Drought planning:A process for state government. Water Resource Bullet in, 1991,27(1): 29-38.

[2] 陈玉琼. 旱涝灾害指标的研究. 灾害学, 1989 (4)。

[3] 鞠笑生, 杨贤为等. 我国单站旱涝指标确定和区域旱涝级别 划分的研究. 应用气象学报, 1997, 8(1)：26-32。

[4] McKee T B, Doesken N J, Kleist J. Drought monitor-ing with multiple timescales. Preprints, 9th Confer-ence on Applied Climatology, 15-20 January, 1995, Dallas, TX, 233-236。

[5] 铜川市计划委员会. 铜川市国土综合开发整治总体规划 [R]. 1998.6。

[6] 铜川市水资源办公室. 铜川市城市供水水源规划 [R]. 1997.8。 
[7] 庞雷. 气候变化对陕西省水资源的影响 $[\mathrm{J}]$. 陕西水力, 2009 (3) : 39-42。

［8］姜悦。近30年铜川市土壤养分时空变异分析 [D]. 西北农林 科技大学. 2014. 5。

［9］王德丽, 殷淑燕, 王海燕等: 近50年来铜川市气候变化特征 分析 $[J]$. 干旱地区资源与环境, 2011, 25 (3) :88-91。

[10] Seiler B A, Hayes M, Bressan L. Using the standardized precip-itation index for flood risk monitoring[J].
International Journal of Climatology, 2002, 22: 1365) 1376 .

[11] 张强, 鞠笑生, 李淑华. 三种干旱指标的比较和新指标的确 定 $[J]$.气象科技, 1998, (2) : 48) 52 。

[12] 韩海涛, 胡文超, 陈学君等: 三种气象干旱指标的应用比较 研究 [J].干旱地区农业研究，2009，27(1) :237-247。 